\title{
Ethylenediamine pretreatment changes cellulose allomorph and lignin structure of lignocellulose at ambient pressure
}

\author{
Lei Qin ${ }^{1,2}$, Wen-Chao Li ${ }^{1,2}$, Jia-Qing Zhu ${ }^{1,2}$, Jing-Nan Liang ${ }^{3}$, Bing-Zhi Li ${ }^{1,2^{*}}$ and Ying-Jin Yuan ${ }^{1,2}$
}

\begin{abstract}
Background: Pretreatment of lignocellulosic biomass is essential to increase the cellulase accessibility for bioconversion of lignocelluloses by breaking down the biomass recalcitrance. In this work, a novel pretreatment method using ethylenediamine (EDA) was presented as a simple process to achieve high enzymatic digestibility of corn stover (CS) by heating the biomass-EDA mixture with high solid-to-liquid ratio at ambient pressure. The effect of EDA pretreatment on lignocellulose was further studied.

Results: High enzymatic digestibility of CS was achieved at broad pretreatment temperature range $\left(40-180^{\circ} \mathrm{C}\right)$ during EDA pretreatment. Herein, X-ray diffractogram analysis indicated that cellulose I changed to cellulose III and amorphous cellulose after EDA pretreatment, and cellulose III content increased along with the decrease of drying temperature and the increase of EDA loading. Lignin degradation was also affected by drying temperature and EDA loading. Images from scanning electron microscope and transmission electron microscope indicated that lignin coalesced and deposited on the biomass surface during EDA pretreatment, which led to the delamination of cell wall. HSQC NMR analysis showed that ester bonds of $p$-coumarate and ferulate units in lignin were partially ammonolyzed and ether bonds linking the phenolic monomers were broken during pretreatment. In addition, EDA-pretreated CS exhibited good fermentability for simultaneous saccharification and co-fermentation process.
\end{abstract}

Conclusions: EDA pretreatment improves the enzymatic digestibility of lignocellulosic biomass significantly, and the improvement was caused by the transformation of cellulose allomorph, lignin degradation and relocalization in EDA pretreatment.

Keywords: Biomass, Pretreatment, Cellulose, Hydrolysis, Lignin, Ethylenediamine

\section{Background}

Lignocellulosic biomass is an abundant resource to produce fermentable sugars and consequent ethanol or other chemical products. The transformation of lignocellulose is beneficial to sustainable energy and environment. Cellulose and hemicellulose, accounting to more than half of total mass in lignocellulose, can be hydrolyzed to fermentable hexose (glucose) and pentose (xylose and

\footnotetext{
${ }^{*}$ Correspondence: bzli@tju.edu.cn

${ }^{2}$ SynBio Research Platform, Collaborative Innovation Center of Chemical Science and Engineering (Tianjin), School of Chemical Engineering and Technology, Tianjin University, Weijin Road 92, Nankai District, Tianjin 300072, People's Republic of China

Full list of author information is available at the end of the article
}

arabinose) by specific enzymes, respectively [1]. However, the enzymatic digestibility of lignocellulose is low due to the structural recalcitrance [2]. Pretreatment is aimed to enhance cellulose conversion by deconstructing biomass structure and thus increasing the accessibility of enzymes and water to the components [3].

Alkaline pretreatments increases enzyme accessibility by degrading lignin and breaking linkage of lignin-carbohydrates [4], in which ammonia pretreatment is widely applied due to the recoverability of ammonia. Ammonia pretreatment employed either aqueous ammonia or liquid ammonia (ammonia fiber expansion, AFEX) [5-7]. Other amines have also been considered effective in pretreatment, such as $\mathrm{N}$-methylmorpholine- $\mathrm{N}$-oxide 
[8], $n$-butylamine and ethylenediamine (EDA) [9]. EDA/ salts system was used to dissolve cellulose [10, 11]. EDA was also coupled with ionic liquid or organic solvent to remove lignin [12]. Besides, EDA has been widely used in changing cellulose allomorph as well as ammonia. Cellulose $I_{\alpha}$ and cellulose $I_{\beta}$ are the predominant allomorphic forms of cellulose found in microbial and plants, respectively. EDA can penetrate the natural crystalline cellulose, break the hydrogen bonds between adjacent cellulose chains and form new hydrogen bonds between EDA and cellulose, and then convert cellulose I to EDAcellulose I complex [13-16]. Upon removing EDA by washing with polar/non-aqueous solvents (e.g., ethanol) or drying under vacuum, the hydrogen bonds reform between cellulose molecules, and the crystal form of cellulose converts to cellulose $\mathrm{III}_{\mathrm{I}}[17]$. Cellulose $\mathrm{III}_{\mathrm{I}}$ can also convert to cellulose I by heating above $200{ }^{\circ} \mathrm{C}$ [18]. It was reported that the enzymatic saccharification rate of cellulose III $_{\text {I }}$ was much higher than cellulose I [19].

In order to achieve high cellulose conversion, most thermochemical pretreatments were carried out at relative high reaction severity, which requires high operating pressures, high temperatures and low biomass concentrations. As the thermal energy consumption in pretreatments almost linearly depends on solid-to-liquid ratio [20], the solid-state pretreatment (with high solid-toliquid ratio) becomes much preferable and promising to improve energy efficiency and reduce water consumption $[21,22]$.

In this study, we developed a new pretreatment method using EDA with a simple process and high solid loading. We explored the pretreatment conditions to improve cellulose conversion, and investigated the mechanism of EDA pretreatment of lignocellulosic biomass. The fundamental insights from this report would be constructive to improve efficiency of lignocellulose hydrolysis.

\section{Results}

\section{Dry method was crucial to increase EDA pretreatment efficiency}

Cellulose allomorphs after the separation of EDA and cellulose were affected by the dry methods [17]. Therefore, different dry methods (air dry, water wash, ethanol wash, and oven dry) were investigated to separate EDA from biomass after 20-min mixing of CS and EDA (1 mL EDA per g CS) at room temperature. The substrate recoveries after pretreatment and sugar yields after enzymatic hydrolysis were measured (Fig. 1, Additional file 1: Table S1). Glucan recoveries were above $98 \%$ after all the separation methods, which is different from the EDA/salts dissolution effect of cellulose $[10,11]$. Xylan recoveries were all above $95 \%$ except for oven-dried CS, in which $19 \%$ xylan degraded to soluble xylo-oligomer. Acid-insoluble lignin (AIL) recovery of oven-dried CS was $48 \%$ and obviously lower than other drying methods (Fig. 1a) implied that xylan and AIL degradation was promoted at high temperature. Glucose and xylose yields of pretreated CS were all higher than the untreated CS ( $23 \%$ for glucose and $21 \%$ for xylose) after $72 \mathrm{~h}$ enzymatic hydrolysis (Fig. 1b). Oven-dried CS exhibited higher glucose yield $(84 \%)$ and xylose yield (55 \%) than other drying methods. The higher sugar yields were consistent with the higher degradation of xylan and AIL.

To clarify whether the xylan and AIL content influenced sugar yields, two different substrates, hemicellulose-free corn stover (HFCS) and corn stover cellulose (CSC) were used to repeat the drying experiments (Fig. 2). CSC was prepared by acid hydrolysis to
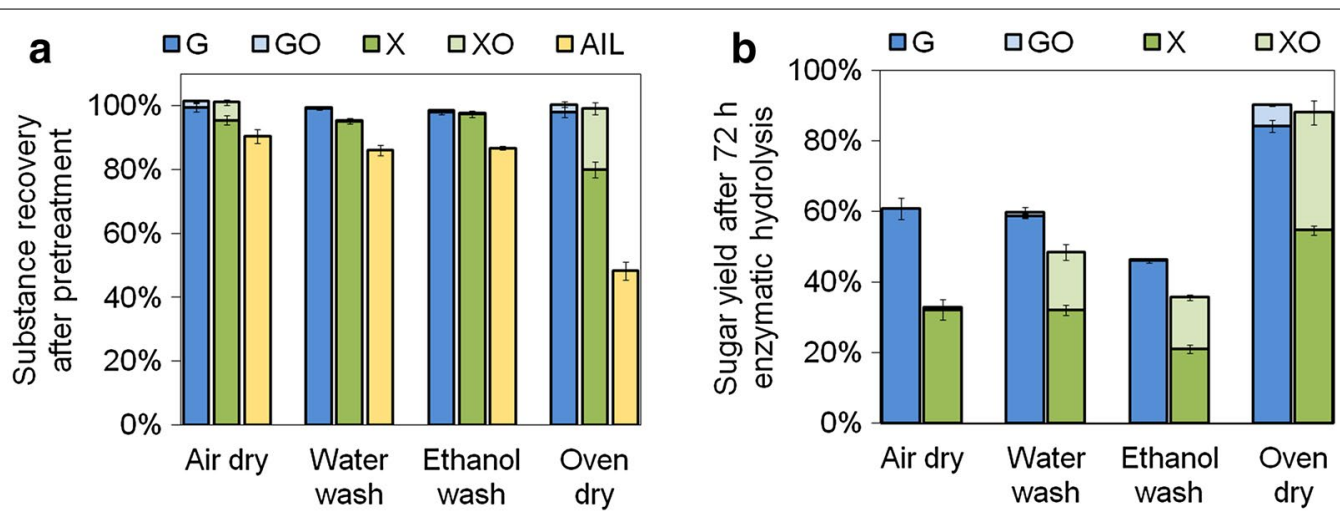

Fig. 1 Effect of EDA separation methods on substance recoveries of CS after pretreatment (a) and sugar yields after following enzymatic hydrolysis (b). EDA loading was $1.0 \mathrm{~mL} / \mathrm{g}$ biomass. EDA was separated from biomass with different methods before uniform mixing for $20 \mathrm{~min}$ at $20^{\circ} \mathrm{C}$. Airdrying was carried out at $20^{\circ} \mathrm{C}$ in fume hood for $120 \mathrm{~h}$. Water-washing and ethanol-washing were carried out by washing with water and ethanol, respectively, with a solid-to-liquid ratio of 1:10 (g:mL) for 3 times to remove EDA, followed by air-drying at room temperature in fume hood. Oven drying was carried out at $120^{\circ} \mathrm{C}$ in oven for $30 \mathrm{~min}$. G glucan, GO gluco-oligmer, Xxylan, XO xylo-oligomer, All acid-insoluble lignin 

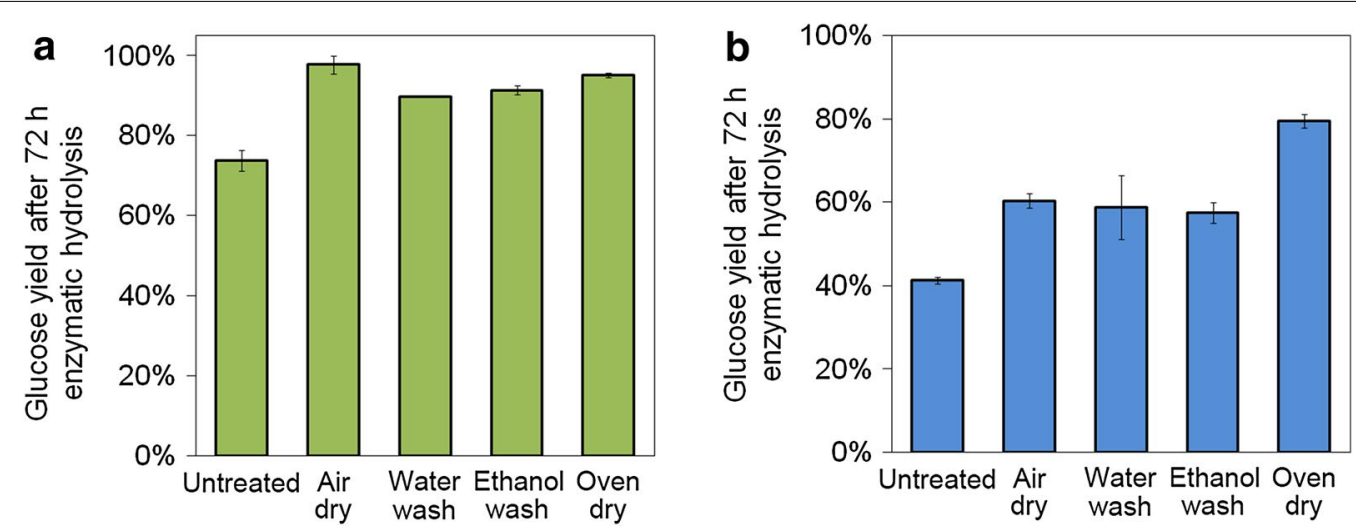

Fig. 2 Effect of EDA separation methods on glucose yield after $72 \mathrm{~h}$ enzymatic hydrolysis using different substrates: a corn stover cellulose (CSC), b hemicellulose-free corn stover (HFCS)

remove hemicellulose followed by chlorite acid bleaching to remove lignin. Glucose yield after 72-h hydrolysis of oven-dried HFCS increased 32, 35, and $92 \%$ with respect to air-dried, water-washed, and untreated HFCS, respectively, which was consistent with the pattern of $\mathrm{CS}$ as substrate. However, digestibility of oven-dried CSC was comparable to air-dried and water-washed CSC. Therefore, we speculated that lignin played important role in enzymatic digestibility improvement in EDA pretreatment. Without lignin in cellulose substrate (i.e., CSC), glucose yields were similar among various drying methods. However, when lignin was not removed in substrate (i.e., HFCS and CS), the lignin content significantly affected the glucose yield.

\section{Pretreatment temperature and EDA loading impact sugars yield}

The effect of temperature on the substance recovery and enzymatic hydrolysis was explored. We standardized the
EDA pretreatment into two processes: (1) reaction process of EDA and biomass in closed container; (2) drying process on open plate. The reaction process (20 min in this study) ensured the adequate contact of EDA with CS, while the drying process ensured removal of EDA from CS. Several temperatures below the EDA boiling point were tested in the drying process (Fig. 3). Drying times were varied at different temperatures in order to remove EDA from pretreated solids as much as possible (Fig. 3). Along with the increase of pretreatment temperature from 20 to $100{ }^{\circ} \mathrm{C}$, AIL recovery successively decreased from 90 to $57 \%$, and conversion of xylan to xylo-oligomer increased from 6 to $18 \%$. Subsequent sugar yield after 72-h hydrolysis successively increased (glucose yield from 61 to $89 \%$ and xylose yield from 33 to $62 \%$ ) and glucose yield exceeded $80 \%$ beyond $60{ }^{\circ} \mathrm{C}$. This result indicated that EDA pretreatment was effective to enhance cellulose digestibility at moderate temperatures. It was noticeable that solid recoveries after pretreatment were $110-120 \%$ under these drying temperatures, indicating an
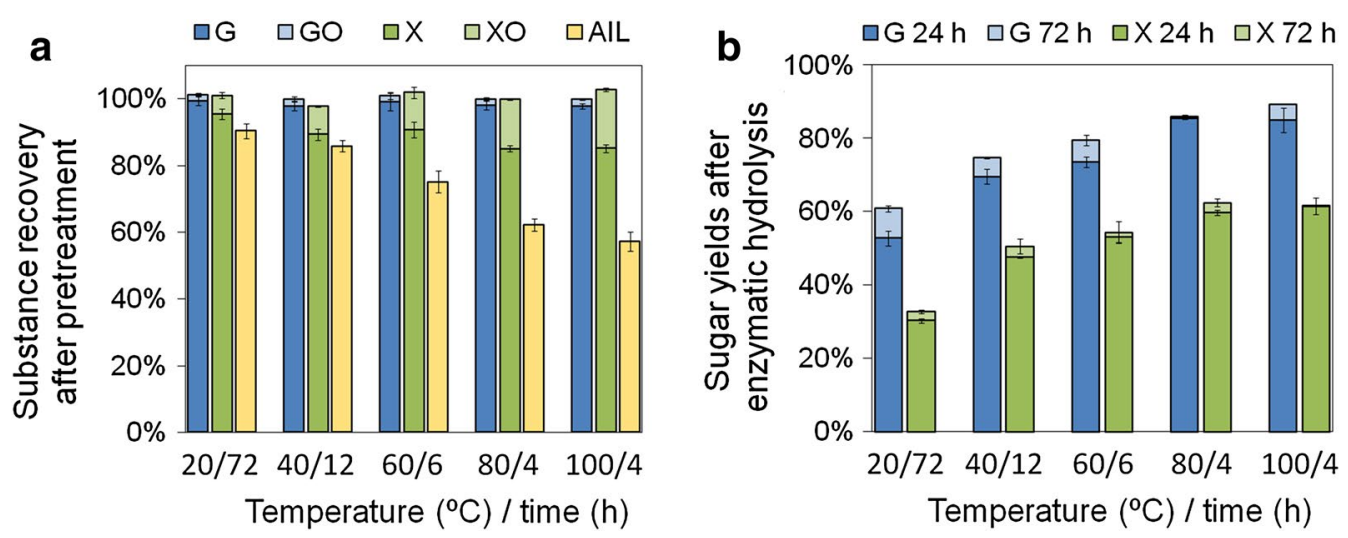

Fig. 3 Effect of drying temperatures and times on substance recoveries in the pretreatment (a) and sugar yields in the following enzymatic hydrolysis (b). EDA loading was $1.0 \mathrm{~mL} / \mathrm{g}$ biomass. The mixture was held at designated temperature in aluminum foil covered plate for 20 min followed by open drying at each condition. G glucan, GO gluco-oligmer, X xylan, XO xylo-oligomer, AlL acid-insoluble lignin 
evident part of EDA remained in pretreated solid (control trials of pretreatment at the same conditions without EDA addition showed $100 \%$ solid recoveries).

In order to reduce the residence of EDA and shorten the drying process, the effect of higher dry temperatures above EDA boiling point $\left(120-180{ }^{\circ} \mathrm{C}\right)$ and lower EDA loadings $(0.2-0.6 \mathrm{~mL} / \mathrm{g}$ biomass) was investigated (Fig. 4, Additional file 1: Table S2). Reducing EDA loading showed great adverse effect on sugars yield. When EDA loading was reduced from 1.0 to 0.6
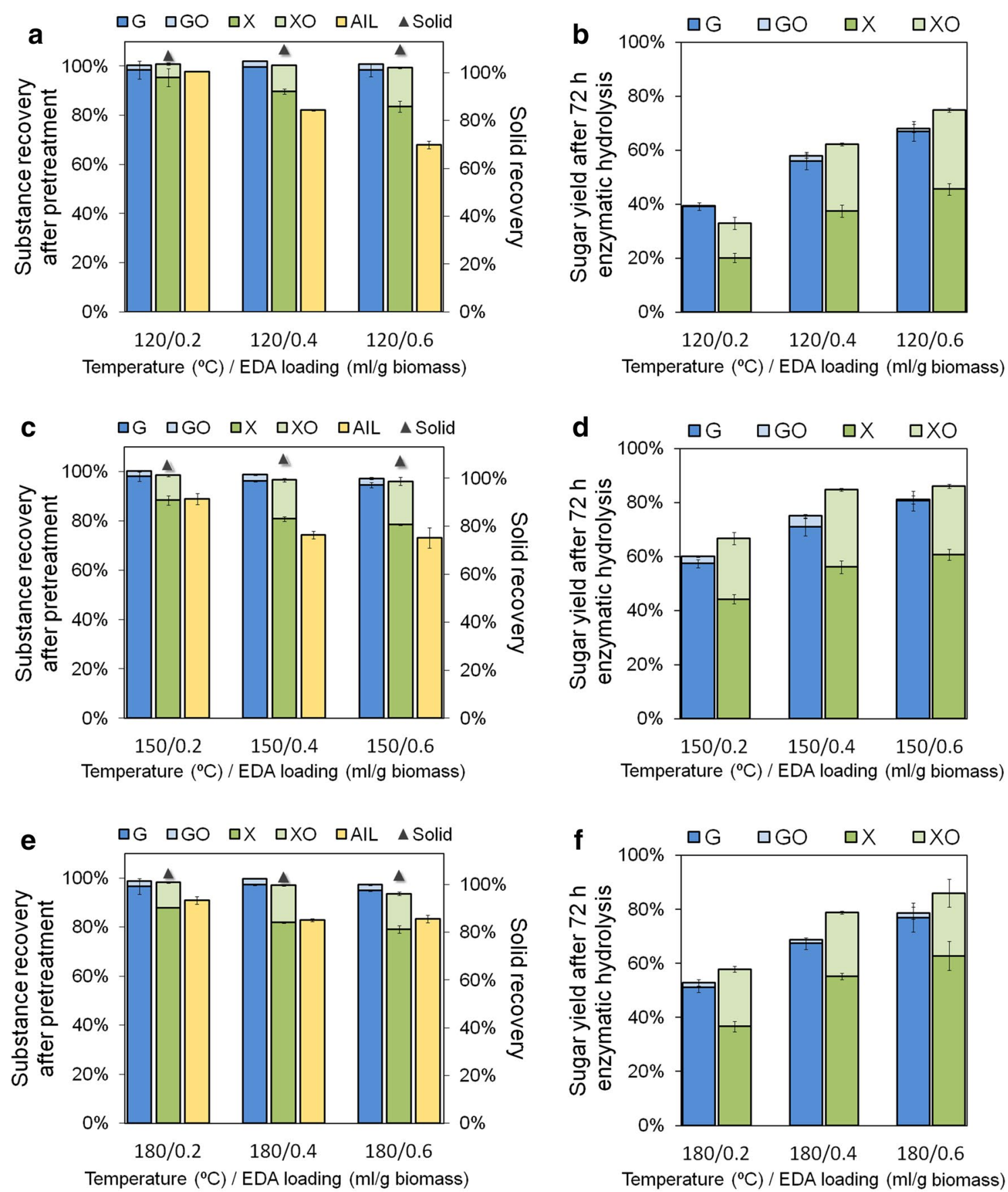

Fig. 4 Effect of pretreatment temperatures and EDA loadings on substance recoveries after pretreatments (a, $\mathbf{c}$, e) and sugar yields in the following enzymatic hydrolysis $(\mathbf{b}, \mathbf{d}, \mathbf{f})$. The mixture was held at designated temperature in aluminum foil covered plate for 20 min followed by drying in open plate for 20 min at designated temperature 
and to $0.2 \mathrm{~mL} / \mathrm{g}$ biomass, glucose yield at 72-h hydrolysis after drying at $120{ }^{\circ} \mathrm{C}$ decreased from 89 to $67 \%$ and to $39 \%$, respectively (Figs. 1b, 4b). The decrease of sugar yield along with the EDA loading reduction was also observed for the biomass drying at $150{ }^{\circ} \mathrm{C}$ and $180{ }^{\circ} \mathrm{C}$. This result revealed that EDA loading is the key factor for the pretreatment and it was inadequate until $1.0 \mathrm{~mL} / \mathrm{g}$ biomass. In contrast to low temperatures, AIL recovery increased from 120 to $180{ }^{\circ} \mathrm{C}$, perhaps because the lignin degraded less efficiently during rapid gasification of EDA at higher temperatures. Solid recovery after pretreatment decreased as the temperature increased $(109,105$, and $102 \%$ with respect to 120,150 , and $180{ }^{\circ} \mathrm{C}$ at EDA loading of $0.6 \mathrm{~mL} / \mathrm{g}$ biomass, respectively), reflecting EDA residue in the solids reduced.

\section{Cellulose allomorphs}

Deconvolution of X-ray diffractogram was applied to figure out the transformation of allomorphic forms with various EDA separation methods (Fig. 5). The fitted curves were highly matched to measured curves $\left(R^{2}\right.$ was greater than 0.99 for each sample). It was observed that cellulose of untreated CS was composed of cellulose I with characteristic peak (110), (1Ī0), and (020) at Bragg angle of around $14.8^{\circ}, 16.3^{\circ}$, and $22.2^{\circ}$, respectively. Amorphous cellulose peak was much broader with maximum intensity around $21^{\circ}$. The untreated cellulose contained $47 \%$ cellulose I and $53 \%$ amorphous cellulose (crystallinity index, CI, is 0.47 ) calculated by peak areas. Cellulose allomorph after EDA soaking and air-dry process was cellulose III $_{\mathrm{I}}$ with characteristic peak (110) and $(020)$ at $11.3^{\circ}$ and $20.3^{\circ}$, respectively. Cellulose $\mathrm{III}_{\mathrm{I}}$

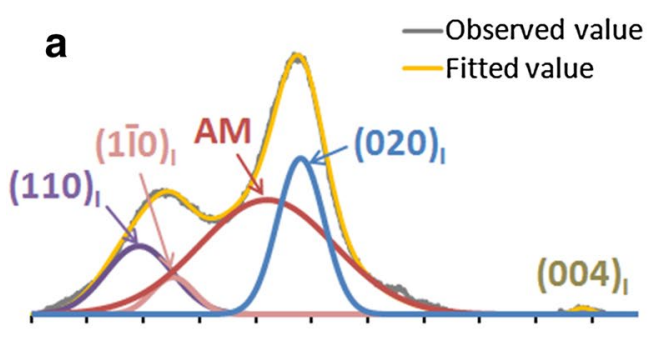

$\begin{array}{lllllllllll}10 & 12.5 & 15 & 17.5 & 20 & 22.5 & 25 & 27.5 & 30 & 32.5 & 35\end{array}$ $2 \theta\left(^{\circ}\right)$

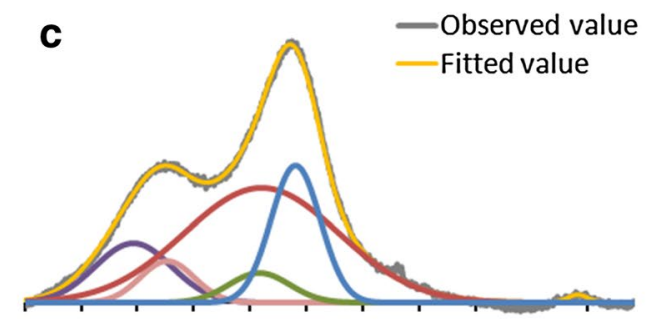

$\begin{array}{lllllllllll}10 & 12.5 & 15 & 17.5 & 20 & 22.5 & 25 & 27.5 & 30 & 32.5 & 35\end{array}$ $2 \theta\left({ }^{\circ}\right)$

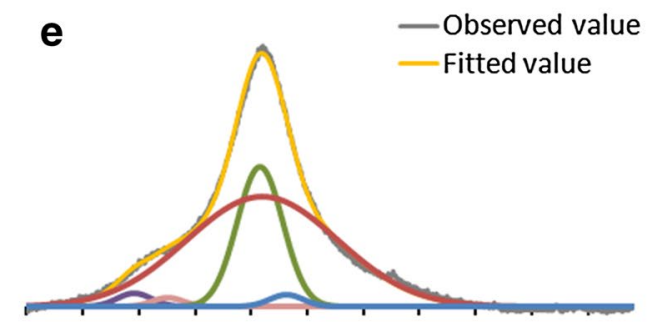

$\begin{array}{lllllllllll}10 & 12.5 & 15 & 17.5 & 20 & 22.5 & 25 & 27.5 & 30 & 32.5 & 35\end{array}$ $2 \theta\left({ }^{\circ}\right)$

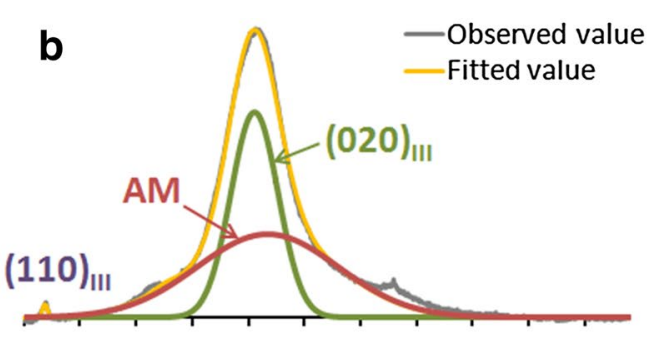

$\begin{array}{lllllllllll}10 & 12.5 & 15 & 17.5 & 20 & 22.5 & 25 & 27.5 & 30 & 32.5 & 35\end{array}$ $2 \theta\left({ }^{\circ}\right)$

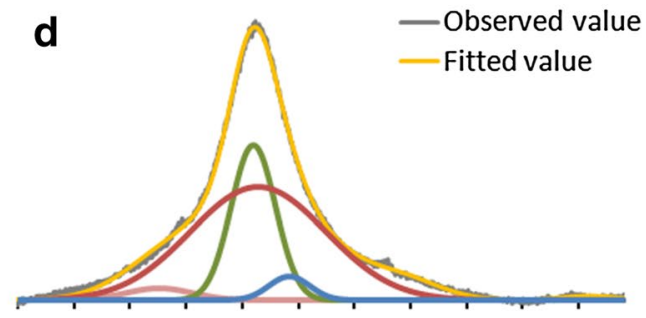

$\begin{array}{lllllllllll}10 & 12.5 & 15 & 17.5 & 20 & 22.5 & 25 & 27.5 & 30 & 32.5 & 35\end{array}$ $2 \theta\left({ }^{\circ}\right)$

\begin{tabular}{llll}
\hline & $\mathrm{I}(\%)$ & $\mathrm{III}$ (\%) & AM (\%) \\
\hline A (untreated) & 47 & 0 & 53 \\
B (60 $\mathrm{C}$ dry) & 0 & 34 & 66 \\
C (water wash) & 37 & 10 & 53 \\
D (EtOH wash) & 3 & 28 & 69 \\
E (120 $\mathrm{C}$ dry) & 2 & 29 & 69 \\
\hline
\end{tabular}

Fig. 5 X-ray diffraction profiles. a untreated CS; b EDA-soaked CS followed by drying at $60^{\circ} \mathrm{C} ; \mathbf{c} \mathrm{EDA}$-soaked CS followed by water-washing and airdrying; d EDA-soaked CS followed by ethanol-washing and air-drying; e EDA-soaked CS followed by drying at $120^{\circ} \mathrm{C}$. AM amorphous cellulose 
accounted for $20 \%$ in this cellulose and another $80 \%$ was amorphous cellulose $(\mathrm{CI}=0.2)$. However, cellulose allomorph after pretreatments was a mixture of cellulose I and cellulose III $_{\mathrm{I}}$ in many cases. Cellulose of EDA-soaked CS followed by water-washing contained $37 \%$ cellulose I and $10 \%$ cellulose III $_{\mathrm{I}}$. During the transformation of EDA-soaked cellulose to cellulose $\mathrm{III}_{\mathrm{I}}, 3$ and $2 \%$ cellulose I was still present for ethanol-dry and oven-dry process, respectively.

The content of cellulose allomorphs was also obviously influenced by pretreatment temperature and EDA loading (Table 1). With EDA loading increasing, content of cellulose III $_{\text {I }}$ and amorphous cellulose increased, and content of cellulose I decreased. These tendencies were observed for pretreated CS at 120,150 , and $180{ }^{\circ} \mathrm{C}$. Furthermore, with pretreatment temperature increasing from 20 to $100{ }^{\circ} \mathrm{C}$, content of amorphous cellulose decreased and content of cellulose III $_{\mathrm{I}}$ increased, which is agreed with previous report [23]. When temperature was higher than $100{ }^{\circ} \mathrm{C}$, content of cellulose I began to increase while content of cellulose III $_{\mathrm{I}}$ decreased. The same results were also observed using Avicel as the substrate (Additional file 1: Table S3).

\section{Morphological changes of the pretreated CS}

Stereoscope images of untreated and pretreated CS are shown in Fig. 6. The pretreated CS became dark brown compared to untreated CS. No other visible change in morphology was observed.

The representative images from scanning electron microscopy (SEM) and transmission electron microscopy (TEM) were selected from more than ten images of each sample. The microstructures of pretreated CS on SEM images exhibited significant differences from the untreated

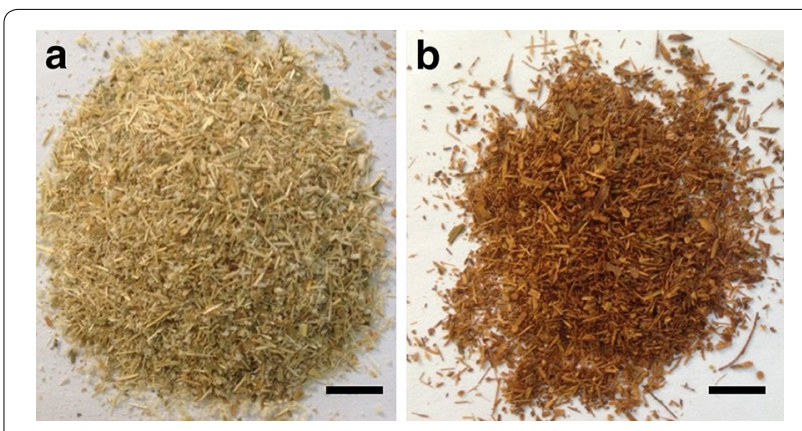

Fig. 6 Untreated CS (a) and pretreated CS (b). EDA loading: $1.0 \mathrm{~mL} / \mathrm{g}$ biomass; temperature: $120^{\circ} \mathrm{C}$; closed reaction for $20 \mathrm{~min}$ and then open drying for $20 \mathrm{~min}$. Scale bars $1 \mathrm{~cm}$

CS (Fig. 7). The surface of untreated stem (Fig. 7a) and leaf (Fig. 7b) was smooth. In contrast, the surfaces of EDApretreated stem (Fig. 7c) and leaf (Fig. 7d) were rough with convex configuration and corrugated appearance (arrow in Fig. 7c, e). The similar morphology was reported for AFEX pretreatment [24]. It was interesting that volcano-like holes were found at some pieces of pretreated CS (arrow in Fig. 7f), which is different from stoma on the leaf (dotted arrow in Fig. 7b, d). The holes were probably formed by the gasification of EDA in the biomass during drying process. The holes were prone to occur at the thin and ductile cell walls, such as corn husk. The pretreated CS after washing revealed that the rough substance on surface was soluble and removable (Fig. 7g, h). In AFEX-pretreated biomass, this similar soluble substance was confirmed to be rich in lignin and hemicellulose $[25,26]$. After washing, the fibrils were clear and slightly separated from each other. Besides the surface changes, no obvious changes of the particle size were observed.

Table 1 Crystalline cellulose and amorphous cellulose contents of pretreated CS at different pretreatment conditions

\begin{tabular}{lllll}
\hline Pretreatment temparature $\left({ }^{\circ} \mathbf{C}\right)$ & EDA loading $(\mathbf{m L} / \mathbf{g}$ biomass) & Cellulose I (\%) & Cellulose III (\%) & Amorphous cellulose (\%) \\
\hline 120 & 0.2 & 32 & 15 & 53 \\
120 & 0.4 & 27 & 20 & 53 \\
120 & 0.6 & 25 & 22 & 53 \\
120 & 0.8 & 15 & 23 & 62 \\
120 & 1 & 2 & 29 & 69 \\
20 & 1 & 5 & 20 & 75 \\
40 & 1 & 3 & 32 & 65 \\
60 & 1 & 0 & 34 & 65 \\
80 & 1 & 0 & 35 & 63 \\
100 & 1 & 0 & 37 & 53 \\
120 & 0.6 & 25 & 22 & 58 \\
150 & 0.6 & 28 & 14 & 54 \\
180 & 0.6 & 33 & 13 & 5 \\
\hline
\end{tabular}



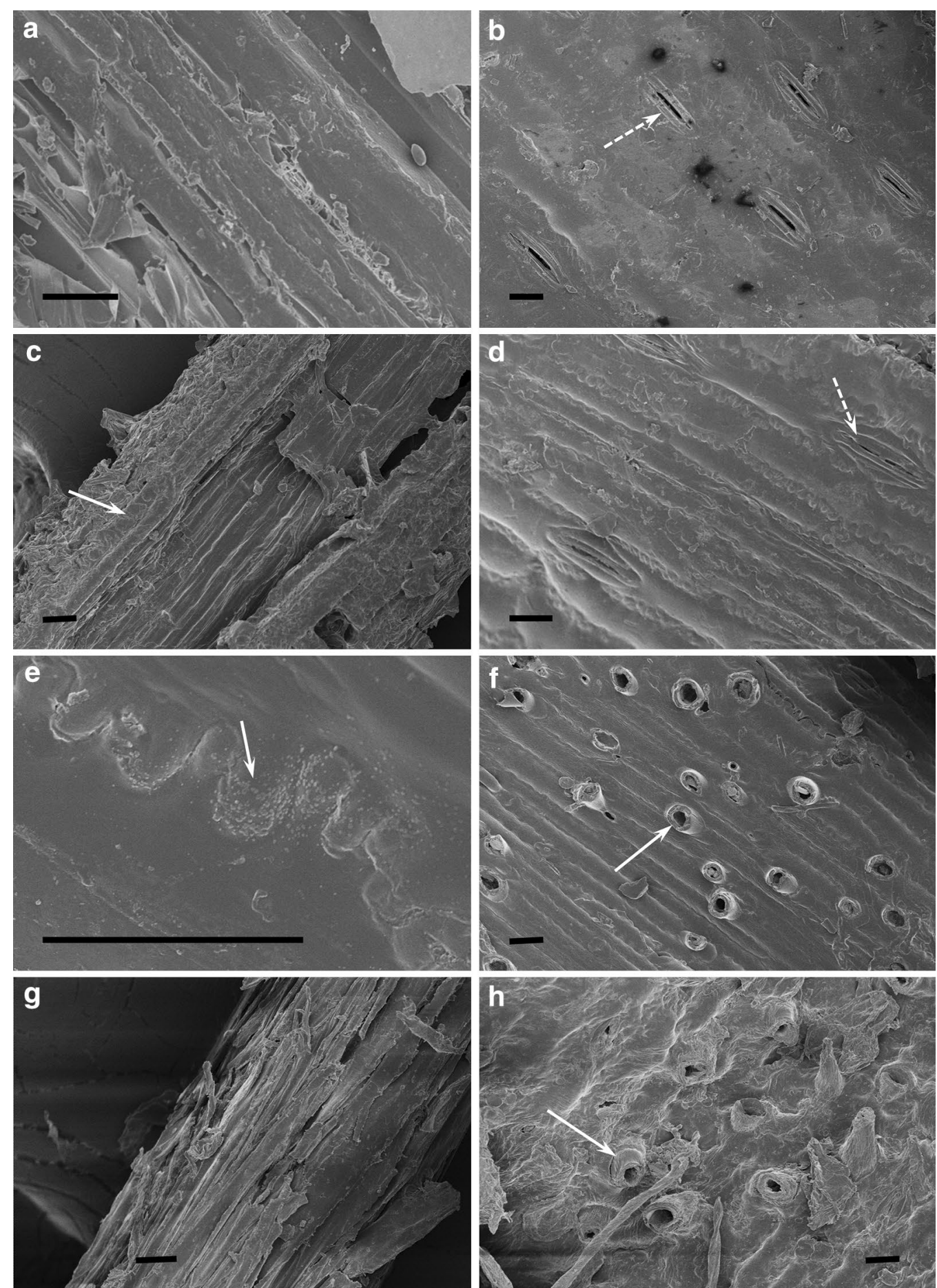

Fig. 7 SEM images of untreated CS $(\mathbf{a}, \mathbf{b})$, pretreated CS $(\mathbf{c}, \mathbf{d}, \mathbf{e}, \mathbf{f})$ and pretreated CS followed by water-washing $(\mathbf{g}, \mathbf{h})$. Scale bars $20 \mu \mathrm{m}$

TEM images further showed the cell wall changes during EDA pretreatment (Fig. 8). Untreated cell walls displayed relatively uniform staining pattern across the cell wall layers, indicating the fine distribution of lignin in cell corners, compound middle lamella, and secondary wall layers (Fig. 8a). The cell walls of the pretreated samples showed the dramatic evidence for lignin re-localization. For the cell walls after pretreatment at $120^{\circ} \mathrm{C}$, coalesced 


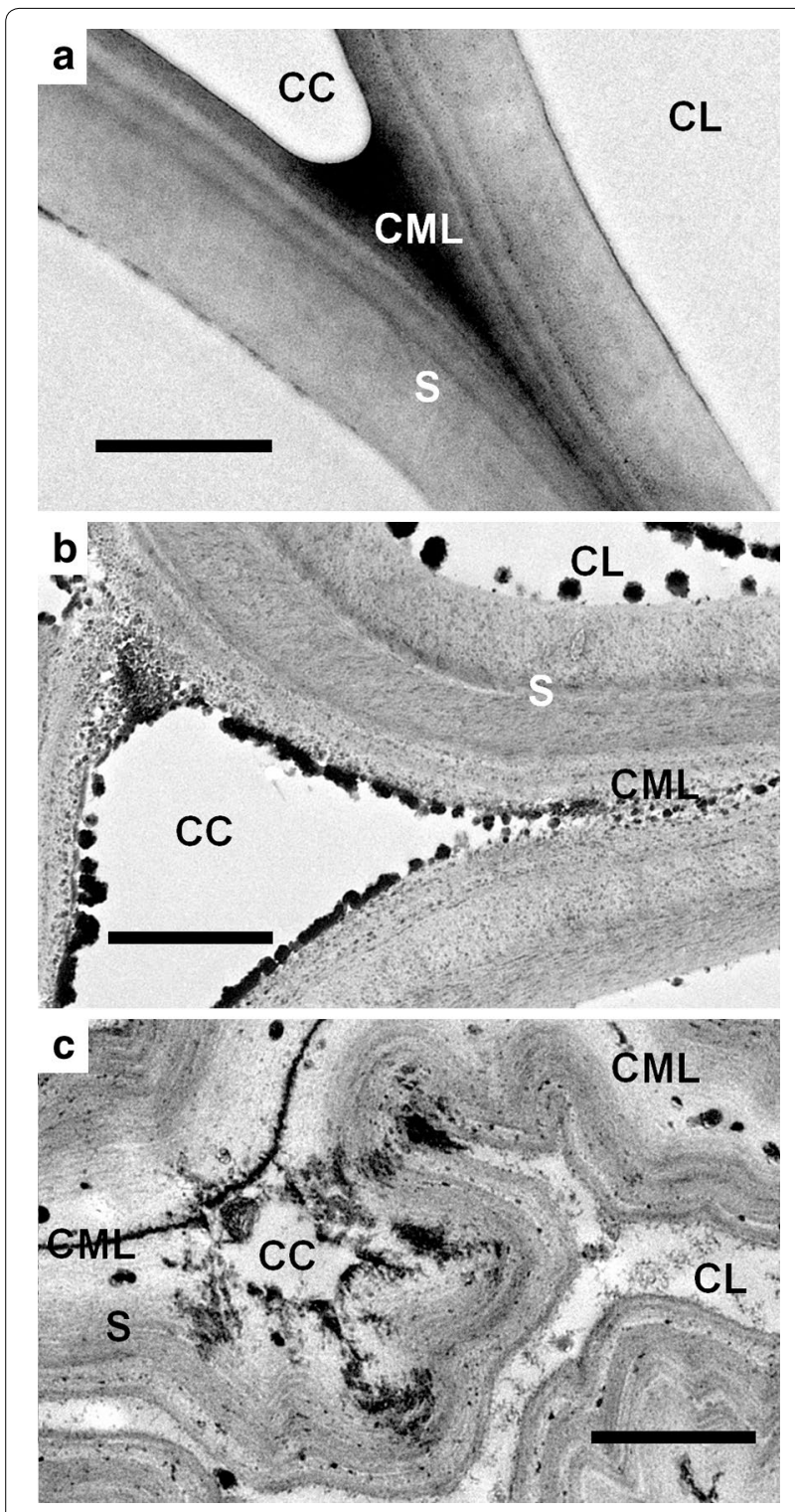

Fig. 8 TEM images of untreated CS (a) and pretreated CS at $120^{\circ} \mathrm{C}$ (b) and $150^{\circ} \mathrm{C}$ (c). CC cell corners, CL cell lumen, CML compound middle lamella, $S$ secondary wall layers. Scale bars 1 Hm lignin-rich globules (up to hundreds of nanometers in diameter) were extruded outwards from the secondary wall layers and deposited on the cell wall surface (Fig. 8b), which is consistent with the SEM images. The lignified globules with similar size have been reported for dilute acid pretreated CS [27]. Cell walls after pretreatment at $150{ }^{\circ} \mathrm{C}$ showed kinking and curling (bending deflection) secondary walls and delamination pores in the secondary wall layers (Fig. 8c). The coalesced lignin on the cell wall surfaces presented not spherical but core-corona structure (one theory is lignin hydrophobic core and polysaccharide hydrophilic corona) [28], which is similar to the structure of AFEX and liquid hot water pretreatment $[25,28]$.

\section{NMR analysis}

In order to characterize the changes of lignin, main aromatic groups $\left(\delta_{\mathrm{C}} / \delta_{\mathrm{H}} 150-90 / 8.0-6.0\right.$, Fig. 9a, c) and inter-unit structures $\left(\delta_{\mathrm{C}} / \delta_{\mathrm{H}} 90-50 / 6.0-2.0\right.$, Fig. 9b, d) of isolated dioxane lignin (DL) were determined by $2 \mathrm{D}$ HSQC NMR. Chemical shift assignments of various lignin moieties were referred to previous studies [2933]. In the aromatic region, DL isolated from untreated CS (Fig. 9a) was constituted by guaiacyl unit (G), syringyl unit $(\mathrm{S})$, tricin $(\mathrm{T}), p$-coumarate $(p \mathrm{CA})$, and ferulate (FA), which was consistent with typical features of most herbaceous lignin. The cross peaks of $\delta_{\mathrm{C}} / \delta_{\mathrm{H}} 103.9 / 6.7$ and $\delta_{\mathrm{C}} / \delta_{\mathrm{H}} 110.8 / 6.97$ were assigned to ${ }^{13} \mathrm{C}-{ }^{1} \mathrm{H}$ correlations of $\mathrm{S} 2 / 6, \mathrm{G} 2$. Signals from $\mathrm{T}$ were identified at $\delta_{\mathrm{C}} / \delta_{\mathrm{H}}$ 94.1/6.56 (T8), $\delta_{\mathrm{C}} / \delta_{\mathrm{H}} 98.8 / 6.22(\mathrm{~T} 6), \delta_{\mathrm{C}} / \delta_{\mathrm{H}} 104.04 / 7.30$ (T $2^{\prime} / 6$ '). Several ${ }^{13} \mathrm{C}-{ }^{1} \mathrm{H}$ correlations of $p \mathrm{CA}$ were identified at $\delta_{\mathrm{C}} / \delta_{\mathrm{H}} 130.0 / 7.47$ ( $p$ CA $\left.2 / 6\right), \delta_{\mathrm{C}} / \delta_{\mathrm{H}} 115.5 / 6.79$ $(p \mathrm{CA} 3 / 5), \delta_{\mathrm{C}} / \delta_{\mathrm{H}} 144.7 / 7.47(p \mathrm{CA} \alpha)$. For EDA-pretreated CS (Fig. 9b), T structure and most $p$ CA/FA structures were diminished. $p$-Coumaroyl amide $\left(p \mathrm{CA}^{\prime}\right)$ and feruloyl amide $\left(\mathrm{FA}^{\prime}\right)$, which are derived from $p \mathrm{CA}$ and FA, respectively, were observed at $\delta_{\mathrm{C}} / \delta_{\mathrm{H}} 129.2 / 7.47$ and $\delta_{\mathrm{C}} / \delta_{\mathrm{H}} 139.7 / 7.47$. The inter-units of lignin mainly composing of $\beta-\mathrm{O}-4$ were found in the aliphatic regions of the HSQC spectrum of untreated CS (Fig. 9c). The signals of $\delta_{\mathrm{C}} / \delta_{\mathrm{H}} 71.8 / 4.8, \delta_{\mathrm{C}} / \delta_{\mathrm{H}} 82-88 / 4.5-3.9$, and $\delta_{\mathrm{C}} / \delta_{\mathrm{H}} 59.4 / 3.4$ were ascribed to the correlation of a position of $\mathrm{A} \alpha-\mathrm{OH}$, $\beta$ position of $\mathrm{A}-\mathrm{H} / \mathrm{G} / \mathrm{S}$, and $\mathrm{A} \gamma$ in $\beta-\mathrm{O}-4$ structure. The contours around $\delta_{\mathrm{C}} / \delta_{\mathrm{H}} 65-62 / 4.5-4$ were assigned to the acylation at $\gamma-\mathrm{OH}$ by $p \mathrm{CA}$ and acetate. Trace amount of correlation signals from dibenzodioxocin (D) was detected at $\delta_{\mathrm{C}} / \delta_{\mathrm{H}} 83.4 / 4.9$. In pretreated CS, the signals attributed to $\beta-\mathrm{O}-4$ and $5-5^{\prime}$ structures were diminished (Fig. 9d), implying the linkages between the lignin monomers were cleaved and the lignin molecular weight was decreased.

\section{Ethanol fermentation and mass balance}

The pretreated CS was subjected to simultaneous saccharification and co-fermentation (SScF) (Fig. 10). Surprisingly, EDA accelerated glucose and xylose utilization in ethanol fermentation at EDA concentration of 1-10 g/L (Additional file 1: Figure S1). At 96 h in SScF, 209 g ethanol was produced based on $1 \mathrm{~kg}$ dry matter of untreated CS. 12 g glucan and 7 g xylan was lost after pretreatment. 24 g glucan and 11 g xylan remained in the residue and $47 \mathrm{~g}$ xylose in hydrolysate (including oligomer) was not utilized after SScF process. Ethanol metabolic yield (based on hydrolyzed glucan and xylan) and ethanol yield 


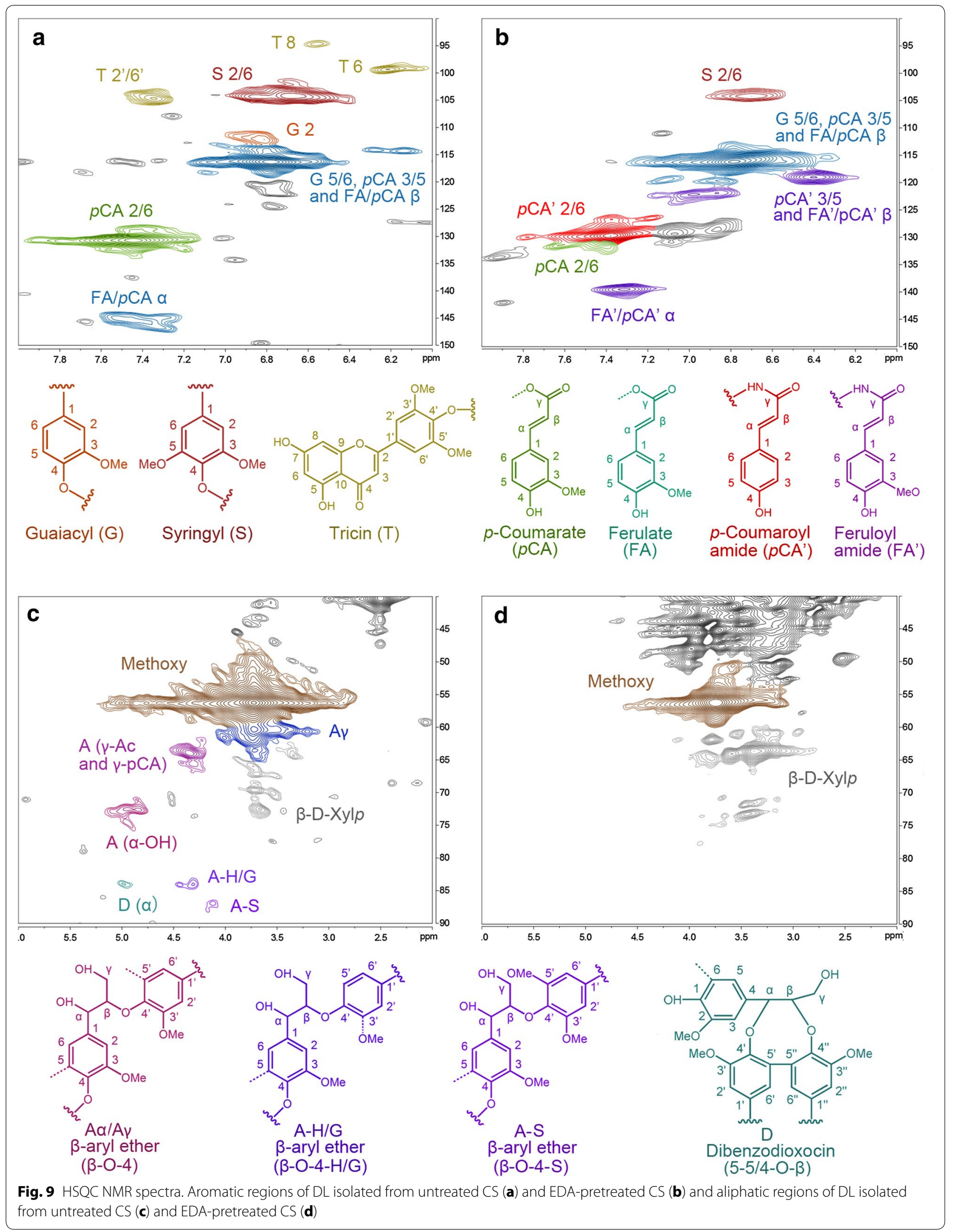




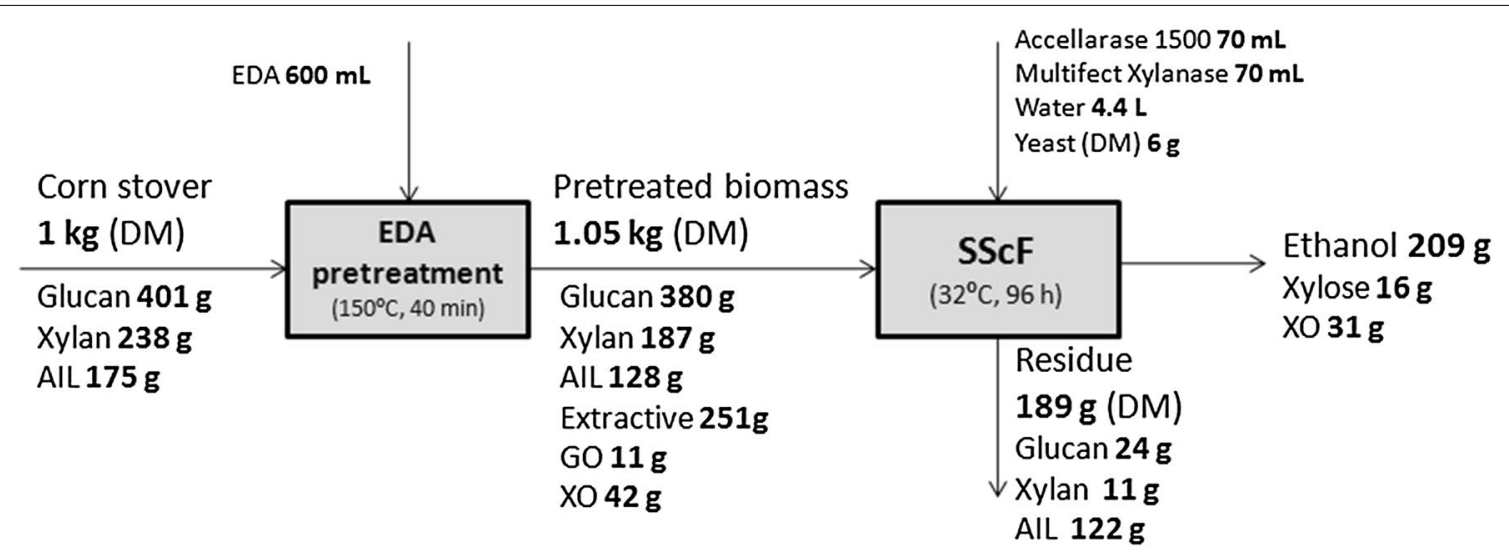

Fig. 10 Mass balance from raw CS to ethanol by EDA pretreatment and SSCF process. SSCF was conducted at $6 \%$ glucan loading. DM dry matter, All acid-insoluble lignin, GO gluco-oligomer, XO xylo-oligomer

(based on glucan and xylan in untreated CS) were 77 and $57 \%$, respectively.

\section{Discussion}

As expected, EDA converted cellulose I to cellulose $\mathrm{III}_{\mathrm{I}}$ except using water-washing (Fig. 5), which agreed with previous report [17]. Cellulose I was increased as pretreatment temperature increasing (Table 1). EDA-cellulose I complex gradually returned to cellulose I when heating temperature above $130{ }^{\circ} \mathrm{C}$. Our findings further demonstrated that EDA loading and temperature also affected the content of cellulose III $_{\mathrm{I}}$ and amorphous cellulose (Table 1). During EDA pretreatment, low EDA loading $\left(<1 \mathrm{~mL} / \mathrm{g}\right.$ biomass) changed cellulose I to cellulose $\mathrm{III}_{\mathrm{I}}$ incompletely. According to previous research, a monoclinic unit cell of cellulose I-EDA crystal is composed of one anhydrous glucose residue and one EDA molecule [16], and only about $0.1 \mathrm{~mL}$ EDA/g biomass was incorporate into cellulose per g CS. However, the practical loading we used was much higher than the expected loading. This may be determined by the thermodynamic equilibrium between cellulose and EDA. The similar loading was used for AFEX pretreatment: about $1 \mathrm{~g}$ ammonia per $\mathrm{g}$ biomass, in which lower ammonia loading resulted in a decreased cellulose conversion as well [5]. Besides allomorph transformation, EDA pretreatment significantly reduced $\mathrm{CI}$, which was also benefit to cellulose digestibility (Table 1, Additional file 1: Figure S2). EDA molecules preferentially penetrate the hydrophilic edges of the stacked sheets and enlarge cellulose $\mathrm{III}_{\mathrm{I}}$ volume in their (010) direction [15] and thus increase the accessibility to water. It was reported that the enzymatic saccharification rate of cellulose $\mathrm{III}_{\mathrm{I}}$ was about 5 times higher than cellulose I [19]. However, other studies found that initial rates of digestion were strongly correlated with amorphous content, not the allomorph type [23, 34]. In this study, the cellulose with more amorphous cellulose exhibited much higher digestibility than cellulose III (Table 1, Additional file 1: Figure S2). Moreover, cellulose III exhibited an increased digestibility compared to cellulose I (glucan conversions for cellulose I and cellulose III after 72 h enzymatic hydrolysis were 57 and $90 \%$, respectively) (Additional file 1: Figure S3). Our results agreed with previous studies [34] that digestibility of cellulose allomorph decreased as following: amorphous cellulose $>$ cellulose III >cellulose I.

Although EDA changed cellulose allomorph and CI, delignification was another important factor impacting the cellulose digestibility. As pretreatment temperature increasing, glucose yield of pretreated Avicel was decreased as its CI increased (Additional file 1: Figure S2), while glucose yield of pretreated CS increased. The increase of glucose yield of CS is mainly attributed to the AIL content reduction, although CI of pretreated CS still increased as temperature increased (Additional file 1: Figure S2). Previous study showed that lignin plays a more important role than cellulose crystallinity on the digestibility of lignocellulose [35]. Both chemistry and physical barrier of lignin characteristics lead to the inhibition of enzymatic hydrolysis of lignin [36]. Lignin delocalization was found in EDA-pretreated CS (Figs. 7, 8). In EDA pretreatment at low temperature (under $120^{\circ} \mathrm{C}$ ), lignin coalesced to globules in and on the cell walls (Fig. 8b). At higher temperature, more lignin and hemicellulose coalesced and extruded from secondary walls and middle lamella, resulting in kinking and delamination of cell walls with broken holes (Fig. 8c). The sizes of the holes are similar to cellulase and facilitate the accessibility of cellulase [25]. Besides, EDA pretreatment converted $10-50 \%$ of lignin to acid-soluble lignin (Figs. 3, 4). 
The ammonolysis of $p$-coumarate esters and the cleavage of $\beta-O-4$ ethers were the main reactions in EDA pretreatment (Fig. 9), which reduced the lignin molecular weight and increased lignin solubility. The cleavage of ester bonds in FA revealed that the cross-linkage of lignin-carbohydrate complex (LCC) was removed (LCC was mainly linked by FA) [30], which facilitated the delocalization of lignin during EDA pretreatment. The ammonolysis of $p$-coumarate esters was also found in AFEX pretreatment [25]. About $20 \mathrm{mg}$ ammonia/g biomass remained in biomass during AFEX pretreatment, in which about $8 \mathrm{mg}$ ammonia ammonolyzed acetyl linkages, coumarate and ferulate esters to their corresponding amides [6, 37]. In addition, the ammoniation of lignin eliminated its inhibition to cellulase by preventing cross-linking of ligninenzyme interactions [38].

Consequently, we supposed the process of EDA pretreatment (Fig. 11). With the addition of EDA, EDA molecules first penetrate into the cellulose crystal. With increasing temperature, EDA escape from the cellulose crystal and transform cellulose I to cellulose III I $_{\text {I }}$ (Table 1). At the same time, EDA ammonolyze esters into $p$-coumarate amides and cleave the ether linkages in lignin and the ester linkages in LCC (Fig. 9), which promotes lignin degradation and coalescence. With the escape of EDA, lignin extrudes outward and deposits on the surface of cell wall (Figs. 7, 8).

In this study, EDA pretreatment with a high solid-toliquid ratio was elucidated to be effective on enhancing enzymatic hydrolysis of CS without washing, neutralization or detoxification. This pretreatment condition (EDA loading: $1 \mathrm{~mL} / \mathrm{g}$ biomass, temperature: $120{ }^{\circ} \mathrm{C}$ ) is similar to AFEX pretreatment conditions [6, 39]. EDA pretreatment has several favorable features including: most pentose is reserved in pretreated solid than acidic pretreatment, resulting in the effective use of pentose in the subsequent co-fermentation process; EDA is easily recovered and recycled, avoiding environment pollution. The dry pretreatment process (without water) appears to be more water saving. In addition, the pretreatment can be done by heating biomass at nearly atmospheric pressure.

EDA recycle will further improve the potential of the industrial application of EDA pretreatment. 2-9 g EDA remained in $100 \mathrm{~g}$ biomass after drying at high temperature above boiling point (Fig. 4), which will increase the cost of the pretreatment. Except for the consumption of EDA in $p$-coumarate amides and ferulate amides production, part of EDA remained in cellulose observed by IR spectra (Additional file 1: Figure S4). These noncovalent bound EDA could be separated theoretically by increasing drying time or increasing vacuum degree.

\section{Conclusions}

The pretreatment of CS using EDA without high pressure was explored. EDA loading and the pretreatment temperature are the key factors for EDA pretreatment. The improvement of enzymatic digestibility is caused by the effect of EDA on the component of biomass, including: (1) the transformation of cellulose allomorph to cellulose $\mathrm{III}_{\mathrm{I}}$ and amorphous cellulose from cellulose $\mathrm{I}_{\beta}$; (2) alteration of lignin chemical structure, morphological structure and location.

\section{Methods}

\section{Materials}

Corn stover (CS) was harvested in 2012 from the suburb of Tianjin, China. CS was washed, air-dried, and knife milled to pass through a $2-\mathrm{mm}$ round screen and stored in supersacks in room temperature. The prepared CS contains $5 \%$ moisture. The dry matter of CS composed of $40.1 \%$ glucan, $23.8 \%$ xylan, and $17.5 \%$ AIL.

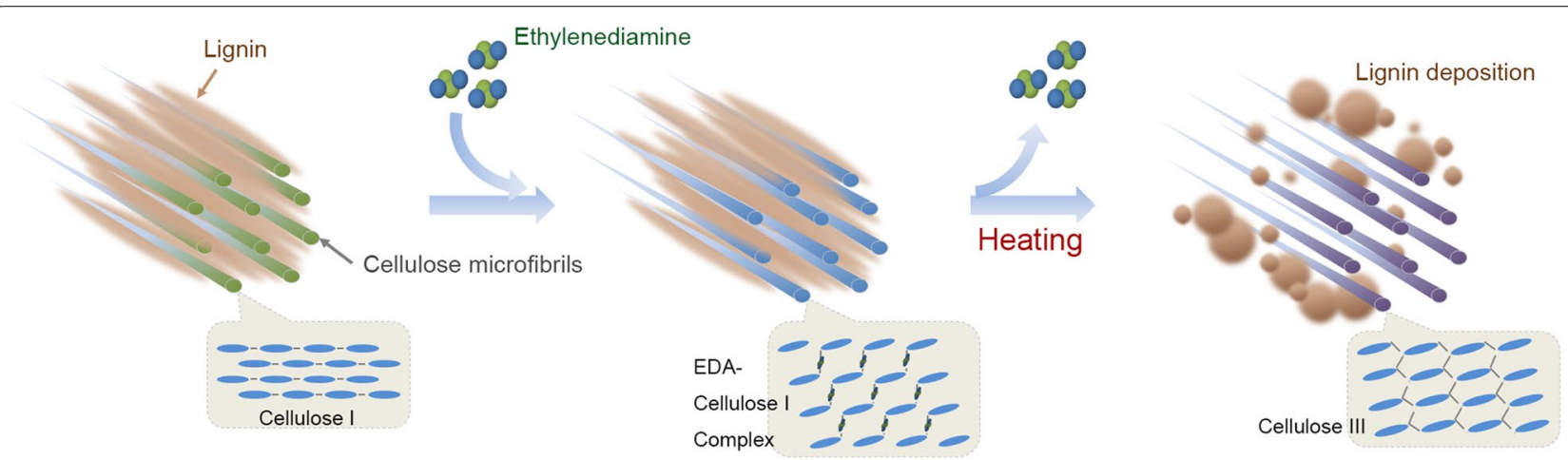

Fig. 11 Schematic model for the effect of EDA pretreatment on lignocellulose. On the one hand, EDA with high temperature promotes lignin relocalization. On the other hand, EDA catalyzes cellulose I to cellulose III. Cellulose crystal lattice was designed based on figures from Wada [17] and Nishiyama [15] 
CSC and HFCS were prepared as control cellulosic substrates according to previous work [23]. In brief, CS was hydrolyzed with $0.6 \%$ sulfuric acid at $130{ }^{\circ} \mathrm{C}$ for $1 \mathrm{~h}$. HFCS was obtained after solid residue was washed exhaustively with distilled water. Further delignification was achieved by treating HFCS with acid chlorite to obtain CSC. HFCS was mixed with sodium chlorite $(0.67 \mathrm{~g} / \mathrm{g}$ biomass $)$ and glacial acetic acid $(1 \mathrm{~mL} / \mathrm{g}$ biomass). The mixture was placed in water bath at $60{ }^{\circ} \mathrm{C}$ for $4 \mathrm{~h}$ with regular mixing. After acid chlorite delignification, the solid residue was water-washed till neutral. CSC and HFCS were air-dried until the moistures less than $10 \%$. Avicel PH-101 also as controlled cellulose was purchased from Sigma-Aldrich (MO, USA). EDA (>99\%) was purchased from Tianjin Yuanli Co., China.

Commercial cellulase Accellerase $1500^{\mathrm{TM}}(89 \mathrm{mg} / \mathrm{mL}$, $77 \mathrm{FPU} / \mathrm{mL}$ ) and hemicellulase Multifect xylanase ${ }^{\mathrm{TM}}$ (42 mg/mL) were gifted by Genencor (NY, USA).

\section{Pretreatment}

Schematic diagram of pretreatment process is shown in Fig. 12. Five grams (dry matter) of CS was mixed with pure EDA in glass plate (diameter $=12 \mathrm{~cm}$ ). Aluminum foil was covered on the plate. The mixture was held in electric oven with designated temperature for $20 \mathrm{~min}$. After this holding time, aluminum foil was taken off to evaporate EDA at the same temperature in the oven for another $20 \mathrm{~min}$. The pretreated CS was achieved without any washing or neutralization steps and subjected to composition analysis, enzymatic hydrolysis, or simultaneously saccharification and co-fermentation.

\section{Chemical composition analysis}

The compositions of untreated and pretreated CS were determined following the Laboratory Analytical Procedure (LAP) of the National Renewable Energy Laboratory (NREL). Glucose and xylose concentrations were determined by HPLC with Aminex HPX-87H column (Biorad, Hercules, CA, USA) at $60{ }^{\circ} \mathrm{C}$ with a mobile phase flow rate of $0.6 \mathrm{~mL} / \mathrm{min}$.

\section{X-ray diffraction (XRD)}

The cellulose allomorph (CA) and crystalline index (CI) was measured using a D8 Fucos X-ray Diffractometer (Bruker AXS Co., Germany). Samples of particle size less than $125 \mu \mathrm{m}$ were scanned at a speed of $4 \% \mathrm{~min}$, range from $2 \theta=10-40^{\circ}$, and with a step size of $0.02^{\circ}$ by positioning the samples on a quartz sample holder using $\mathrm{Cu}$ Ko radiation operated at $40 \mathrm{kV}, 40 \mathrm{~mA}$.

The deconvolution of the resulted diffractogram was performed using software PeakFit (SeaSolve Software Inc.). Gaussian functions were applied in curve fitting analysis.

Estimation of the content of cellulose I, cellulose III, and amorphous cellulose in the cellulosic samples was established by using the following equations:

$$
\begin{aligned}
& \mathrm{I} \%=\frac{\mathrm{A}_{\mathrm{I}}}{\mathrm{A}_{\mathrm{I}}+\mathrm{A}_{\mathrm{III}}+\mathrm{A}_{\mathrm{AM}}} \times 100 \% \\
& \mathrm{III} \%=\frac{\mathrm{A}_{\mathrm{III}}}{\mathrm{A}_{\mathrm{I}}+\mathrm{A}_{\mathrm{III}}+\mathrm{A}_{\mathrm{AM}}} \times 100 \% \\
& \mathrm{AM} \%=\frac{\mathrm{A}_{\mathrm{AM}}}{\mathrm{A}_{\mathrm{I}}+\mathrm{A}_{\mathrm{III}}+\mathrm{A}_{\mathrm{AM}}} \times 100 \%
\end{aligned}
$$

where I \%, III \%, and AM \% are the contents of cellulose I, cellulose III, and amorphous cellulose in samples, respectively; $\mathrm{A}_{\mathrm{I}}, \mathrm{A}_{\mathrm{II}}$, and $\mathrm{A}_{\mathrm{AM}}$ are the peak areas of cellulose I, cellulose III, and amorphous cellulose, respectively.

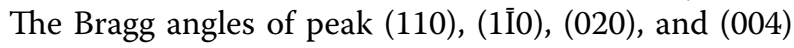
belonging to cellulose I are $14.8^{\circ}, 16.3^{\circ}, 22.3^{\circ}$, and $34.5^{\circ}$, respectively. The Bragg angles of peak (110) and (020) belonging to cellulose III are $11.3^{\circ}$ and $20.0^{\circ}$, respectively. The Bragg angle of amorphous peak is around $20.5^{\circ}[40$, 41].

\section{Scanning electron micrograph (SEM)}

SEM was carried out on a field emission scanning electron microscope (S4800, Hitachi, Co., Japan) after the samples were sputtered with a layer of gold.

\section{Transmission electron micrograph (TEM)}

The methodology of sample preparation was referred to previous works [25, 42]. Samples were fixed in $2.5 \%$ (w/v) glutaraldehyde in $0.2 \mathrm{M} \mathrm{pH} 7.2$ sodium phosphate buffer twice for $6 \mathrm{~min}$ ( $2 \mathrm{~min}$ on, $2 \mathrm{~min}$ off, $2 \mathrm{~min}$ on) at room temperature followed by thoroughly washing with phosphate buffer. Dehydration of samples was achieved by transferring to vials containing a graded water-ethanol series (10\% steps for $30-90 \%$ each of

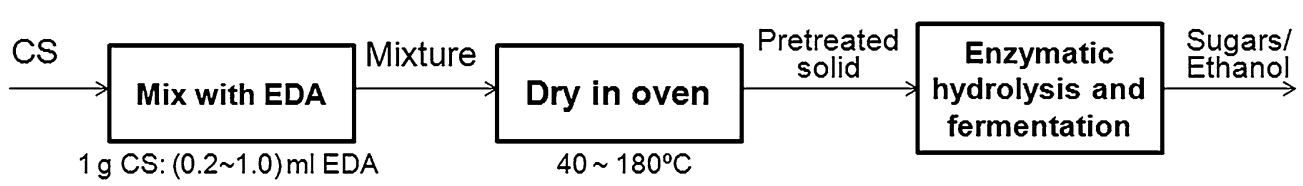

Fig. 12 Schematic diagram for EDA pretreatment and refinery process 
$15 \mathrm{~min}, 100 \%$ for $30 \mathrm{~min})$. After dehydration, the samples were infiltrated with LR White resin in increasing resin concentrations of $15,30,60$, and $90 \%$ resin diluted in ethanol and three times in $100 \%$ resin. The resin-infiltrated samples were transferred to gelatin capsules and polymerized at $60{ }^{\circ} \mathrm{C}$ overnight. LR White-embedded samples were sectioned to $60 \mathrm{~nm}$ with a Diatome diamond knife on a Leica EM UC7 ultramicrotome (Wetzlar, Germany). Sections were collected on formvar-coated grids. Grids were poststained for $10 \mathrm{~min}$ with $1 \%$ aqueous uranyl acetate and 5 min with Reynolds lead citrate. Images were taken with a Gatan UltraScan 1000 camera (Gatan, Pleasanton, CA, USA) on an $80 \mathrm{kV} \mathrm{JEM-1400} \mathrm{transmission}$ electron microscope (JEOL, Japan).

\section{Lignin isolation and 2D NMR analysis}

Lignin in untreated and pretreated CS was isolated following the procedure by Zeng $[29,30]$. CS was milled in a planetary ball mill (DECO, China) with zirconium dioxide balls at $300 \mathrm{rpm}$ for $4 \mathrm{~h}$. The well-ground samples were extracted with ethanol for $12 \mathrm{~h}$ followed by repeated washings to remove extractives. The solids after extraction were air-dried, extracted by dioxane/water solution $(96: 4 \mathrm{v} / \mathrm{v})$ for $48 \mathrm{~h}$ at room temperature, and air-dried. The dioxane soluble lignin (DL) from untreated CS was further purified by dissolving in an acetic acid/water solution $(9: 1 \mathrm{v} / \mathrm{v})$ followed by the precipitation in cold deionized water and freeze-dried.

For each sample, $20 \mathrm{mg}$ of DL was dissolved in $250 \mu \mathrm{L}$ of $99.9 \%$ DMSO- $d_{6}$ with $0.05 \% \mathrm{v} / \mathrm{v}$ TMS as internal standard. The heteronuclear single quantum coherence (HSQC) NMR spectra were recorded on a Varian Inova $400 \mathrm{MHz}$ spectrometer (Agilent Technologies). The spectral width was $7211.5 \mathrm{~Hz}$ for ${ }^{1} \mathrm{H}$ and $31,698 \mathrm{~Hz}$ for ${ }^{13} \mathrm{C}$. The number of scans was 32 with a 512 time increment. The relaxation delay was $0.43 \mathrm{~s}$ and the acquisition time was $0.07 \mathrm{~s}$. Interactive integrations of the peaks in ${ }^{13} \mathrm{C} /{ }^{1} \mathrm{H}$ spectrum and contours in 2D HSQC plots were measured using MestReNova software.

\section{Enzymatic hydrolysis}

Enzymatic hydrolysis was conducted with $20 \mathrm{ml}$ reaction volume and $1 \%$ glucan loading in $100 \mathrm{ml}$ Erlenmeyer flasks. Accellerase 1500 and Multifect xylanase loading were 18 and $9 \mathrm{mg}$ protein/g glucan, respectively. $50 \mathrm{mM}$ citrate buffer (pH 4.8) with $50 \mathrm{mg} / \mathrm{L}$ ampicillin was used. Orbital incubator was set at $45{ }^{\circ} \mathrm{C}$ and $200 \mathrm{rpm} .0 .5 \mathrm{~mL}$ aliquot was withdrawn during enzymatic hydrolysis and was centrifuged at $12,000 \mathrm{rpm}$ for $5 \mathrm{~min}$ to separate hydrolysate from solid residue. Glucose and xylose concentrations in hydrolysates were determined by HPLC with Aminex HPX-87H column.

\section{Simultaneously saccharification and co-fermentation (SScF)}

An engineered yeast S. cerevisiae SyBE005 with genetically constructed xylose utilizing pathway [43] was used in this study. Seed culture was prepared in YPX medium (10 g/L yeast extract, $20 \mathrm{~g} / \mathrm{L}$ peptone and $20 \mathrm{~g} / \mathrm{L}$ xylose) at $30{ }^{\circ} \mathrm{C}$ for $36 \mathrm{~h}$. Inoculation size was $\mathrm{OD}_{600}=4$. Yeast and enzymes (enzymes used the same loading described above) were inoculated to pretreated CS medium with $6 \%$ glucan loading at the same time. Ampicillin with finial concentration of $50 \mathrm{mg} / \mathrm{L}$ was used to prevent bacterial contamination. No other extra nutrient was added to the SScF medium. Experiment was carried out under anaerobic condition using shaking flasks in an orbital incubator at $32{ }^{\circ} \mathrm{C}$ and $150 \mathrm{rpm}$. To release the carbon dioxide produced at early stage, a syringe needle was pierced through the rubber stopper.

\section{Additional file}

Additional file 1. Table S1. Compositions of pretreated CS from different EDA separation methods. Table S2. Compositions of pretreated CS from different temperatures and EDA loadings. Table S3. Crystalline cellulose (cellulose I and cellulose IIII) and amorphous cellulose contents of pretreated Avicel measured by XRD at different pretreatment conditions. Figure S1. Glucose (A), xylose (B), ethanol (C), and EDA (D) concentration during fermentation using S.cerevisiae SyBE005 with synthetic medium ( $20 \mathrm{~g} / \mathrm{L}$ glucose, $10.5 \mathrm{~g} / \mathrm{L}$ xylose, and different concentrations of EDA) Figure S2. Glucose yield in enzymatic hydrolysis of pretreated CS (A), pretreated Avicel (B), acid insoluble lignin recovery of pretreated CS (C), and $\mathrm{Cl}$ of pretreated Avicel (D) have the relationships to pretreatment temperature from $20^{\circ} \mathrm{C}$ to $100^{\circ} \mathrm{C}$. Figure $\mathbf{S 3}$. Glucan conversion of untreated Avicel (cellulose I) and EDA pretreated Avicel at $120^{\circ} \mathrm{C}$ (cellulose III) in enzymatic hydrolysis. Enzymatic hydrolysis was conducted with $20 \mathrm{~mL}$ reaction volume and $1 \%$ glucan loading in $100 \mathrm{~mL}$ Erlenmeyer flasks. Accellerase 1500 loading was $18 \mathrm{mg}$ protein/g glucan. $50 \mathrm{mM}$ citrate buffer ( $\mathrm{pH}$ 4.8) with $50 \mathrm{mg} / \mathrm{L}$ Ampicillin was used. Orbital incubator was set at $45^{\circ} \mathrm{C}$ and $200 \mathrm{rpm}$. Figure S4. FTIR spectra of untreated and EDA pretreated CS and Avicel. Pretreatment temperature was $120^{\circ} \mathrm{C}$. EDA loading was $1 \mathrm{~mL} / \mathrm{g}$ biomass. Drying time was $40 \mathrm{~min}$. Peaks at $1630 \mathrm{~cm}^{-1}$ of EDA-CS and EDA-Avicel stand for C-N vibration in ethylenediamine, indicating ethylenediamine remain in pretreated CS and Avicel.

\section{Abbreviations}

EDA: ethylenediamine; CS: corn stover; CSC: corn stover cellulose; HFCS: hemicellulose-free corn stover; AlL: acid-insoluble lignin; DL: dioxane lignin; SSCF: simultaneous saccharification and co-fermentation; AFEX: ammonia fiber expansion; Cl: crystalline index; AM: amorphous cellulose; HPLC: high performance liquid chromatography; XRD: X-ray diffraction; HSQC NMR: heteronuclear single quantum coherence nuclear magnetic resonance; SEM: scanning electron microscope; TEM: transmission electron microscope; IR: infrared radiation; $H$ : hydroxyphenyl unit; G: guaiacyl unit; S: syringyl unit; T: trincin; $p C A$ : $p$-coumaric acid; FA: ferulic acid; $p C A^{\prime}: p$-coumarate amide; $F A^{\prime}$ : ferulate amide; G: glucan; GO: gluco-oligomer; X: xylan; XO: xylo-oligomer; CC: cell corners; $\mathrm{CL}$ : cell lumen; CML: compound middle lamella; $\mathrm{S}$ : secondary wall layers; LCC: lignin-carbohydrate complex; FPU: filter paper unit.

\section{Authors' contributions}

LQ carried out the pretreatment, enzymatic hydrolysis and XRD, performed the statistical analysis and drafted the manuscript. WCL participated in the pretreatment and enzymatic hydrolysis experiment and revised the manuscript. JQZ carried out the fermentation and revised the manuscript. JNL undertook the electron microscope analysis and helped to revise the 
manuscript. BZL and YJY conceived of the study and revised the manuscript. All authors read and approved the final manuscript.

\begin{abstract}
Author details
1 Key Laboratory of Systems Bioengineering (Ministry of Education), Tianjin University, Weijin Road 92, Nankai District, Tianjin 300072, People's Republic of China. ${ }^{2}$ SynBio Research Platform, Collaborative Innovation Center of Chemical Science and Engineering (Tianjin), School of Chemical Engineering and Technology, Tianjin University, Weijin Road 92, Nankai District, Tianjin 300072, People's Republic of China. ${ }^{3}$ Institute of Microbiology Chinese Academy of Sciences, No.1 West Beichen Road, Chaoyang District, Beijing 100101, People's Republic of China.
\end{abstract}

\section{Acknowledgements}

This study was financially supported by the Ministry of Science and Technology of China ("973" Program: 2013CB733601, 2014CB745102), the National Natural Science Foundation of China (Major program: 21390203). We acknowledge Dr. Ding from Tianjin University for helping with 2D NMR measurement.

\section{Competing interests}

The authors declare that they have no competing interests.

Received: 8 June 2015 Accepted: 14 October 2015

Published online: 29 October 2015

\section{References}

1. Alvira P, Tomás-Pejó E, Ballesteros M, Negro MJ. Pretreatment technologies for an efficient bioethanol production process based on enzymatic hydrolysis: A review. Bioresour Technol. 2010;101:4851-61.

2. Chundawat SPS, Beckham G, Himmel ME, Dale BE. Deconstruction of lignocellulosic biomass to fuels and chemicals. Annu Rev Chem Biomol Eng. 2011;2:121-45.

3. Mosier N, Wyman C, Dale BE, Elander R, Lee YY, Holtzapple M, Ladisch M. Features of promising technologies for pretreatment of lignocellulosic biomass. Bioresour Technol. 2005;96(6):673-86.

4. Bali G, Meng X, Deneff Jl, Sun Q, Ragauskas AJ. The effect of alkaline pretreatment methods on cellulose structure and accessibility. ChemSusChem. 2015;8(2):275-9.

5. Qin L, Liu ZH, Jin MJ, Li BZ, Yuan YJ. High temperature aqueous ammonia pretreatment and post-washing enhance the high solids enzymatic hydrolysis of corn stover. Bioresour Technol. 2013;146:504-11.

6. Lau MW, Dale BE. Cellulosic ethanol production from AFEX-treated corn stover using Saccharomyces cerevisiae 424A(LNH-ST). Proc Natl Acad Sci. 2009;106(5):1368-73.

7. Li BZ, Balan V, Yuan YJ, Dale BE. Process optimization to convert forage and sweet sorghum bagasse to ethanol based on ammonia fiber expansion (AFEX) pretreatment. Bioresour Technol. 2010;101:1285-92.

8. Shafiei M, Karimi K, Taherzadeh MJ. Pretreatment of spruce and oak by $\mathrm{N}$-methylmorpholine- $\mathrm{N}$-oxide (NMMO) for efficient conversion of their cellulose to ethanol. Bioresour Technol. 2010;101:4914-8.

9. Tanaka M, Robinson CW, Moo-Young M. Chemical and enzymatic pretreatment of corn stover to produce soluble fermentation substrates. Biotechnol Bioeng. 1985;27(3):362-8.

10. Xiao M, Frey MW. The role of salt on cellulose dissolution in ethylene diamine/salt solvent systems. Cellulose. 2007;14:225-34.

11. Xiao M, Frey MW. Study of cellulose/ethylene diamine/salt systems. Cellulose. 2009;16:381-91.

12. Padmanabhan S, Zaia E, Wu K, Blanch HW, Clark DS, Bell AT, Prausnitz JM. Delignification of Miscanthus by Extraction. Separ Sci Technol. 2012;47(2):370-6.

13. Numata Y, Kono H, Kawano S, Erata T, Takai M. Cross-polarization/magicangle spinning $13 \mathrm{C}$ nuclear magnetic resonance study of cellulose I-ethylenediamine complex. J Biosci Bioeng. 2003;96(5):461-6.

14. Sawada D, Nishiyama Y, Petridis L, Parthasarathi R, Gnanakaran S, Forsyth VT, Wada M, Langan P. Structure and dynamics of a complex of cellulose with EDA: insights into the action of amines on cellulose. Cellulose. 2013;20:1563-71.

15. Nishiyama Y, Wada M, Hanson BL, Langan P. Time-resolved X-ray diffraction microprobe studies of the conversion of cellulose I to ethylenediamine-cellulose I. Cellulose. 2010;17:735-45.
16. Wada M, Kwon GJ, Nishiyama Y. Structure and thermal behavior of a cellulose I-ethylenediamine complex. Biomacromolecules. 2008;9:2898-904.

17. Wada M, Chanzy H, Nishiyama Y, Langan P. Cellulose III, crystal structure and hydrogen bonding by synchrotron $\mathrm{X}$-ray and neutron fiber diffraction. Macromolecules. 2004;37:8548-55.

18. Wada M. In situ observation of the crystalline transformation from cellulose III, to I . Macromolecules. 2001;34:3271-5.

19. Chundawat SPS, Bellesia G, Uppugundla N, da Costa Sousa L, Gao D, Cheh AM, Agarwal UP, Bianchetti CM, Phillips GN Jr, Langan P, Balan V, Gnanakaran S, Dale BE. Restructuring the crystalline cellulose hydrogen bond network enhances its depolymerization rate. J Am Chem Soc. 2011;133(29):11163-74.

20. Zhu JY, Pan X, Zalesny RS Jr. Pretreatment of woody biomass for biofuel production: energy efficiency, technologies, and recalcitrance. Appl Microbiol Biotechnol. 2010;87:847-57.

21. Zhang J, Wang X, Chu D, He Y, Bao J. Dry pretreatment of lignocellulose with extremely low steam and water usage for bioethanol production. Bioresour Technol. 2011;102:4480-8.

22. Barakat A, Chuetor S, Monlau F, Solhy A, Rouau X. Eco-friendly dry chemomechanical pretreatments of lignocellulosic biomass: Impact on energy and yield of the enzymatic hydrolysis. Appl Energ. 2014;113:97-105.

23. Mittal A, Katahira R, Himmel ME, Johnson DK. Effects of alkaline or liquidammonia treatment on crystalline cellulose: changes in crystalline structure and effects on enzymatic digestibility. Biotechnol Biofuels. 2011;4:41.

24. Lee JM, Jameel H, Venditti RA. A comparison of the autohydrolysis and ammonia fiber explosion (AFEX) pretreatments on the subsequent enzymatic hydrolysis of coastal Bermuda grass. Bioresour Technol. 2010;101:5449-58.

25. Chundawat SPS, Donohoe BS, daCostaSousa L, Elder T, Agarwal UP, Lu F, Ralph J, Himmel ME, Balan V, Dale BE. Multi-scale visualization and characterization of lignocellulosic plant cell wall deconstruction during thermochemical pretreatment. Energ Environ Sci. 2011;4:973.

26. Donohoe S, Decker SR, Tucker MP, Himmel ME, Vinzant TB. Visualizing lignin coalescence and migration through maize cell walls following thermochemical pretreatment. Biotechnol Bioeng. 2008;101(5):913-25.

27. Boukari I, Putaux JL, Cathala B, Barakat A, Saake B, Rémond C, O'Donohue M, Chabber B. In vitro model assemblies to study the impact of lignincarbohydrate interactions on the enzymatic conversion of xylan. Biomacromolecules. 2009;10:2489-98.

28. Donohoe S, Vinzant TB, Elander RT, Pallapolu VR, Lee YY, Garlock RJ, Balan V, Dale BE, Kim Y, Mosier NS, Ladisch MR, Falls M, Holtzapple MT, SierraRamirez R, Shi J, Ebrik MA, Redmond T, Yang B, Wyman CE, Hames B, Thomas S, Warner RE. Surface and ultrastructural characterization of raw and pretreated switchgrass. Bioresour Technol. 2011;102:11097-104.

29. Zeng J, Tong Z, Wang L, Zhu JY, Ingram L. Isolation and structural characterization of sugarcane bagasse lignin after dilute phosphoric acid plus steam explosion pretreatment and its effect on cellulose hydrolysis. Bioresour Technol. 2014;154:274-81.

30. Zeng J, Helms GL, Gao X, Chen S. Quantification of wheat straw lignin structure by comprehensive NMR analysis. J Agric Food Chem. 2013;61:10848-57.

31. Rencoret J, Prinsen P, Gutierrez A, Martinez AT, Del Rio JC. Isolation and structural characterization of the milled wood lignin, dioxane lignin, and cellulolytic lignin preparations from brewer's spent grain. J Agri Food Chem. 2015;. doi:10.1021/jf505808c.

32. Wen JL, Sun SL, Yuan TQ, Xu F, Sun RC. Structural elucidation of lignin polymers of Eucalyptus chips during organosolv pretreatment and extended delignification. J Agri Food Chem. 2013;61(46):11067-75.

33. Huang X, Korányi TI, Boot MD, Hensen EJ. Catalytic depolymerization of lignin in supercritical ethanol. ChemSusChem. 2014;7(8):2276-88.

34. Cui T, Li J, Yan Z, Yu M, Li S. The correlation between the enzymatic saccharification and the multidimensional structure of cellulose changed by different pretreatments. Biotechnol Biofuels. 2014;7:134

35. Liu ZH, Qin L, Li BZ, Yuan YJ. Physical and chemical characterizations of corn stover from leading pretreatment methods and effects on enzymatic hydrolysis. ACS Sustain Chem Eng. 2015;3:140-6.

36. Yu Z, Gwak KS, Treasure T, Jameel H, Chang HM, Park S. Effect of lignin chemistry on the enzymatic hydrolysis of woody biomass. ChemSusChem. 2014;7:1942-50.

37. Chundawat SPS, Vismeh R, Sharma LN, Humpula JF, da Costa Sousa L, Chambliss CK, Jones AD, Balan V, Dale BE. Multifaceted characterization of cell wall decomposition products formed during ammonia fiber 
expansion (AFEX) and dilute acid based pretreatments. Bioresour Technol. 2010;101:8429-38.

38. Sewalt VJH, Glasser WG, Beauchemin KA. Lignin impact on fiber degradation. 3. Reversal of inhibition of enzymatic hydrolysis by chemical modification of lignin and by additives. J Agri Food Chem. 1997;45(5):1823-8.

39. Zhong C, Lau MW, Balan V, Dale BE, Yuan YJ. Optimization of enzymatic hydrolysis and ethanol fermentation from AFEX-treated rice straw. Appl Microbiol Biotechnol. 2009;84:667-76.

40. Park S, Baker JO, Himmel ME, Parilla PA, Johnson DK. Cellulose crystallinity index: measurement techniques and their impact on interpreting cellulase performance. Biotechnol Biofuels. 2010;3:10.
41. Ciolacu D, Gorgieva S, Tampu D, Kokol V. Enzymatic hydrolysis of different allomorphic forms of microcrystalline cellulose. Cellulose. 2011;18:1527-41.

42. Donohoe BS, Selig MJ, Viamajala S, Vinzant TB, Adney WS, Himmel ME. Detecting cellulase penetration into corn stover cell walls by immunoelectron microscopy. Biotechnol Bioeng. 2009;103(3):480-9.

43. Zha J, Shen MH, Hu ML, Song H, Yuan YJ. Enhanced expression of genes involved in initial xylose metabolism and the oxidative pentose phosphate pathway in the improved xylose-utilizing Saccharomyces cerevisiae through evolutionary engineering. J Ind Microbiol Biotechnol. 2013:41:27-39.

\section{Submit your next manuscript to BioMed Central and take full advantage of:}

- Convenient online submission

- Thorough peer review

- No space constraints or color figure charges

- Immediate publication on acceptance

- Inclusion in PubMed, CAS, Scopus and Google Scholar

- Research which is freely available for redistribution

Submit your manuscript at

www.biomedcentral.com/submit

(O) Biomed Central 